\title{
Designs on the Web: a case study of online learning for design students
}

\author{
S. Brown, C. H. M. Hardaker and N. P. Higgett \\ De Montfort University \\ email:chh@dmu.ac.uk
}

The De Montfort University Electronic Campus initiative started in September 1999. Web-based learning resources and support have been provided for over 3,000 students via a portfolio of thirty projects ranging across all levels of the university and within every faculty. This paper focuses on one aspect of this initiative: the development of online teaching and learning materials to support first-year IT modules for students of art and design. An undergraduate module has been converted from traditional, face-to-face, delivery to a hybrid combination of Web-based and studio-based work in accordance with Laurillard's conversational framework. In the first year of use all the new material has been made available on a pilot basis to a group of 440 students in parallel with conventional lectures and seminars. All the students have had access to the online resources; some students have used them, but some have not. Data on student expectations collected prior to starting on the module are compared with student feedback gathered at the end of the module and student performance data across the two modes of presentation are compared to establish the relative effectiveness of each approach. In addition the paper reviews the resource implications of developing, delivering and supporting online learning and discusses some of the barriers to implementation that were encountered and overcome.

\section{Introduction}

As governments, companies and individuals come to recognize the contribution of learning to economic success and competitiveness, $\mathrm{HE}$ institutions are under increasing pressure to increase access to a larger number and a greater variety of students. Today, rapid technological development means that knowledge is soon outdated and employees need to enhance their attractiveness through periodic self-development. In order to remain competitive employers need to update the skills of their workforce, as does the nation state. In 
recent years many publications have argued the need to replace traditional patterns of education with the more flexible concept of Lifelong Learning (HMSO, 1998; DfEE, 1998a).

Lifelong learning means increasing numbers of individuals who need to access educational opportunities for irregular periods, fitting study around domestic and employment commitments. This is also true of many full-time students who increasingly have to fit their studies around paid work. Thus traditional modes of operation for $\mathrm{HE}$, fixed attendance at lectures, limited opening hours for buildings, communication via notice boards, face-toface meetings, seminars and tutorials all create barriers to ready access for people in such situations. The challenge, therefore, is to find some way of maintaining traditional values while simultaneously responding to the call for increased (and different) participation, at lower cost.

The convergence of different media into a single networked digital domain, the rapidly expanding accessibility of such media and dramatic reductions in cost, are tempting many institutions to develop an online presence. The Western Governors' University (www.wgu.edu), Colorado University's CU Online (www.cuonline.edu) and commercial organizations such as Phoenix University (www.uophx.edu/online) and ZD University (www.zdu.com), with their potential to deliver globally, are indications of the possible shape of things to come. The Internet appears to offer learners the opportunity to study whenever they like and wherever they have access to a terminal, not just via traditional oncampus locations as dictated by the timetable. The addition of email, computer conferencing and video conferencing can assist this process by providing the discursive element identified by Laurillard (1993) as crucial to the success of academic learning.

The De Montfort University Electronic Campus initiative aims to exploit the properties of online technology to enhance the flexibility of access to learning opportunities and support for students on campus. This is an important distinction: rather than a move into the arena of distance learning it is an attempt to exploit the properties of online technologies to enhance the quality of traditional provision through mixed mode delivery. It is doing this by providing a substantial body of Web-based teaching, learning, and assessment materials, plus appropriate learning support systems. These encourage and facilitate peer group interaction and staff-student exchanges, independent of time and specific university location as far as possible but without losing the advantage of real staffstudent contact and peer interaction characteristic of a traditional university (Brown, 1998).

\section{Development of the teaching and learning content}

The Faculty of Art and Design has been actively involved in the development of Webbased teaching and learning materials since 1995. With funding from the STILE (Student and Teachers Integrated Learning Environment) project, a CD-ROM and Web-support materials were developed for two lectures within a module (Zhao, Higgett and Cook, 1996). This was followed by the development of a framework for an online learning environment for a complete module. This work was also supported by STILE and included lectures, search facilities, bulletin boards, text conferencing and tests (severn.dmu.ac.uk/ nick/STILE/IDE/main.HTM). Evaluation of this work showed that students performed equally as well (in some cases better) using the online environment, 
compared with those students attending the traditional lectures (Georgeadou and Higgett, 1997; 1998).

The work reported in this paper sets out to build on this understanding of students' needs through the creation of an online learning resource for four first-year modules, which introduce it to fashion designers, three-dimensional designers, design managers and multimedia designers. These modules are taught over a twelve-week teaching semester and are run twice in an academic year. Class contact time per week includes a one-hour lecture and a two-hour practical session. This paper is primarily concerned with the development of the learning content and initial testing of this resource.

\section{Student expectations of online learning: the initial study}

Students' opinions on the use of Web-based teaching and learning materials were sought from the 1997-8 cohort who completed the Level 1 module using traditional teaching and learning strategies. This was done using a questionnaire (see Appendix 1). Students were asked to rate how useful they thought it would be to have various teaching and learning materials online, such as lecture transcripts, practical notes and module handbooks. The requirement for face-to-face contact was considered and students were asked if they would prefer to study online lectures independently as opposed to attending a traditional lecture series. Finally students were asked if they had Internet access at their term- time address and if they would like to see their second-year Computer Aided Design (CAD) modules online. One-hundred responses to the questionnaire were obtained, approximately 22 per cent of the 1997-8 cohort taking the four Level 1 IT modules. Of these respondents, a high proportion ( 20 per cent) had Internet access at their term-time address.

The expectation survey revealed that the majority of respondents were positively disposed towards online resources. They thought that all the proposed aspects of an online learning resource would be useful to some degree (see Figure 1), and nearly all (91 per cent) were keen to see second-year CAD modules online.

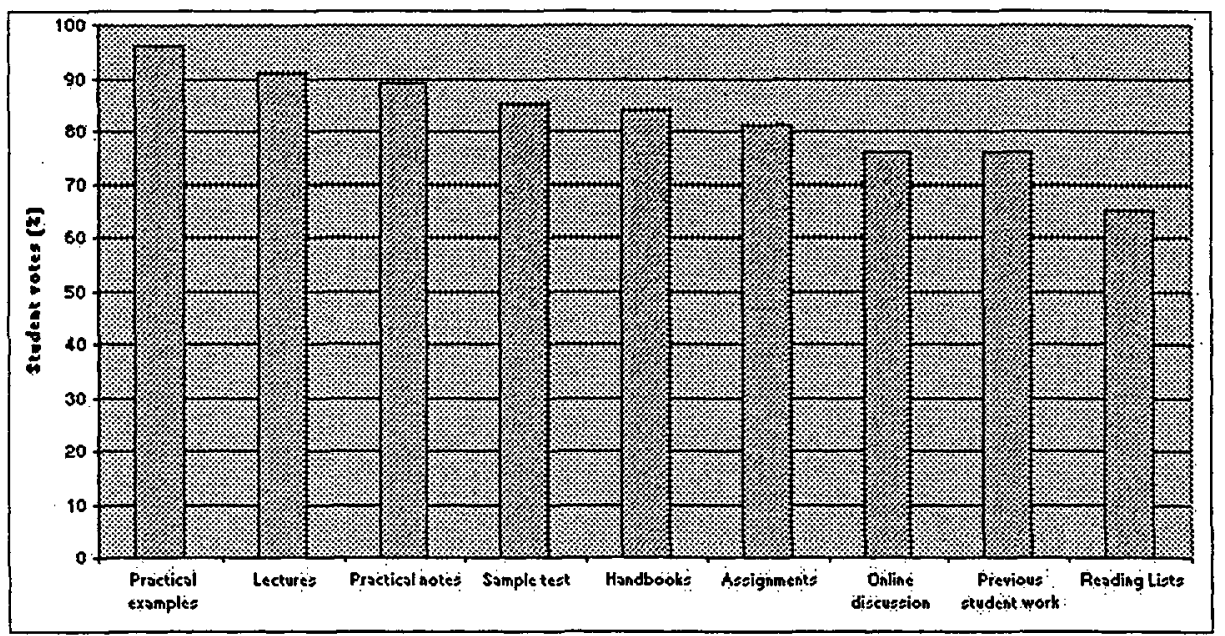

Figure 1: Student response to the question of how useful online resources would be 
Over 80 per cent of respondents stated that online versions of the practical examples, lecture transcripts, practical notes, sample test and assignments would be useful. However, when asked if an online learning resource should be used to replace the traditional lecture, only 18 per cent said they would be happy to study the lecture material independently using solely the online resource. Over three-quarters of respondents (79 per cent) opted to keep the face-to-face contact, with over half ( 55 per cent) saying that they would use the online resource as extra study material. This confirmed the earlier findings (Georgeadou and Higgett, 1997; 1998) and is in line with conventional wisdom that face-to-face lectures are best. Nearly as many respondents (76 per cent) thought that access to online discussion groups and previous student work would be useful. Online reading lists received the lowest percentage of votes although even here 65 per cent of respondents regarded them as being useful.

\section{Developing the teaching and learning resource}

The content for the courseware was split into distinct categories:

- the handbook for each module;

- a common set of lectures (text and images) for all four modules, to introduce the theory behind the use of IT in design;

- separate software tutorials to support the IT practicals for each module.

The more discursive elements of email, conferencing and online assessments were not tackled at this stage.

The module handbooks set the learning context, outlining the module aims, timetables, reading lists, expected learning outcomes, assessment methods and criteria for each module. These documents were already in Microsoft Word format and could be easily integrated into the new Web-site. However lecture notes in most parts were in the form of hand-written notes. These had to be word-processed and edited with suitable illustrations and test questions so that they could act as a stand-alone learning resource. This required at least ten hours per lecture for the authors.

The following software tutorials, aimed at skills acquisition were developed:

- Adobe Photoshop for the fashion and textiles module;

- $3 D$ studio for the three-dimensional design module;

- Adobe Photoshop and Macromedia Director for the multimedia design module;

- Quark Xpress for the design management module.

Initially it was intended to create animated software tutorials with voice-overs using Lotus Screen Cam. However, after experimentation it was decided that the size of these files (as much as four or five Mbytes per minute) was too great given the present speed of the network. Thus the tutorials were developed using text and still screen shots, each two-hour tutorial taking 25-30 hours to produce.

All this material was then given to an external Web design company for authoring into the final application. To maximize the use of available funds, a low-cost start-up company of De Montfort University graduates was used. 
Several problems were encountered during the development stage. The main problem was shortage of staff time to provide the content. Even though funding was available it was impossible in most cases to release full-time teaching staff to develop the lecture content. This was mainly due to the difficulty in finding suitable part-time staff to take over existing teaching commitments and meant full-time staff involved in the project had extra work added to an already heavy workload. The available funding was used mainly for the development of tutorials for the practical classes, which were normally delivered by part-time staff.

The large number of authors involved in the project, four full-time and five part-time members of staff, led to a further problem in co-ordinating a large number of inputs. This combined with the heavy workload on authors meant that content was not always handed over on schedule for production. This was compounded by the fact that the external production company was a start-up operation and was unable to provide a consistent uninterrupted service. This resulted in materials being available online sometimes only hours before they were needed and meant that there was no time to evaluate and refine the materials before usage. It was felt that these problems with team working could have been overcome by more in-house Web development support or Web development training for staff on the development side.

\section{Results from the first year of use}

The effects of using the Web-based teaching and learning materials were assessed by canvassing student opinion and analysing student performance.

\section{Student opinion}

Following completion of the modules by the first cohort (1998-9), a feedback questionnaire was administered to ascertain students' opinions of the online learning materials at the end of each teaching semester (see Appendix 2). The survey aimed to ascertain how useful the new site had been, and how useful a number of proposed additional features would be. Students were also asked where they gained access to the site and if, after seeing the online materials for Level 1, they would like to see their Level 2 CAD module online. A total of 248 questionnaires were completed, approximately 54 per cent of the total number of students taking the Level 1 IT modules.

The feedback questionnaire revealed that most respondents ( 82 per cent) used the online resource as part of their study, with the same percentage keen to see a second-year CAD module online. Comparing use between design disciplines, 92 per cent of those studying three-dimensional design used the resource, whereas the other disciplines of design management, fashion and textiles and multimedia design had lower utilization percentages; these were 83,79 and 75 per cent respectively. Many reasons could be attributed to the differences across disciplines. Lack of networking in the laboratories used by design management and fashion and textiles students is likely to have contributed to their lower use of the resource.

Despite the surprisingly high level of Internet access at home, most respondents used university resources to access the site either in the CAD laboratory ( 39 per cent) or in the Kimberlin Library ( 37 per cent). Smaller percentages used their own ( 9 per cent) or a friend's computer (15 per cent). 
Considering the responses of students from all design disciplines it can be seen that the rank ordering of different elements was identical to the results of the expectation survey. In practice, the lecture transcripts were seen to be the most useful aspect of the existing online resource ( 85 per cent), followed by the practical notes ( 70 per cent), handbooks ( 52 per cent) and finally the reading lists (49 per cent).

Potential additional features were also rated. The most useful additions were considered to be further practical examples ( 86 per cent), a gallery of previous student work ( 85 per cent) and a sample test ( 85 per cent). Online discussion facilities scored the lowest number of students' votes in the useful or very useful categories ( 60 per cent).

The IT for fashion and textiles module is run at the Leicester City campus and at a franchise college. However, because of the large discrepancy in student numbers studying the module at the two sites (140 at Leicester and 8 at the franchise college) it was felt unwise to compare the results from the feedback questionnaire. However the results do show that the majority of students, irrespective of location, have used Web-based learning materials and viewed the features of the current site useful.

\section{Student performance}

A statistical analysis was performed to assess if there was any significant difference in marks attained by a cohort studying the module with access to Web-based learning materials and the cohort studying the modules using traditional learning strategies. Average mark comparisons were made between the design disciplines in the 1997-8 cohort and the 1998-9 cohort.

The null hypothesis that the student marks came from the same population was asserted. Student's $t$ test for the equality of means was performed using SPSS. The average mark for each design discipline and the two tailed significance of the difference in means are given in Table 1.

\begin{tabular}{lccc}
\hline Student group & Average mark, 1997-8 & Average mark, 1998-9 & Significance \\
\hline Fashion and Textiles & 50.9 & 54.8 & 0.004 \\
Three Dimensional Design & 58.5 & 54.2 & 0.025 \\
Multimedia Design & 57.1 & 61.2 & 0.036 \\
Design Management & 55.2 & 52.3 & 0.101 \\
\hline
\end{tabular}

Table 1: Comparison of average marks between cohort, 1997-8 and cohort, 1998-9

It can be seen that at a significance level, $p=0.01$ there is no significant change in results for the groups between years except for fashion and textiles. This group shows a significant increase in performance of 4 per cent. Thus for most disciplines it appears that student performance is similar before and after the introduction of Web-based learning materials.

\section{Discussion}

The analysis of the expectation and feedback questionnaires indicated that design students taking IT modules were positively disposed towards online learning resources. While this view is hardly surprising given the nature of the topic itself, it is in contrast to the view held 
by some staff that students require extrinsic motivation to use new technologies (Littlejohn and Stefani, 1999). The site provides students with an assurance that they have access to all the notes accompanying the module and so if some part of the traditional teaching is missed, the notes are easy to access. The teaching and learning content developed for the site is also of use as a source of reference to other undergraduate and postgraduate students within the Faculty of Art and Design.

It was clear from the expectation survey that students do not wish face-to-face lectures to be replaced by online resources. In addition, the results from the feedback questionnaire revealed that the inclusion of online discussion facilities were not considered as useful as other features such as further practical examples and samples of past work. This is interesting given the importance often attached to staff-student and peer group discussion (Laurillard, 1993) and may be because students at present have little or no experience of using online discussion and plenty of opportunities for face-to-face discussions on campus. The attitude of students towards the need for the traditional lecture may change given exposure to a development complete with discursive elements.

The majority of students used campus-based university computing facilities to access the resource, despite high expectation of home use. This may be due to students' concerns over the cost of modem access to the Internet. This is one aspect of a wider issue revealed by Bacsich, Ash, Boniwell and Kaplan (1999), namely the ways in which online learning transfers costs to students (and staff) and it seems likely to dominate student access patterns until fixed cost or truly free access to the Internet becomes available. This behaviour appears to confirm and reinforce De Montfort's policy decision not to establish the Electronic Campus as a 'virtual university'.

The statistical analysis of average marks for each module before and after the introduction of the online resource showed student performance remained similar over the two years. In fact one discipline, fashion and textiles, showed a significant improvement in marks. This is encouraging although it is not possible to attribute these results solely to the provision of online learning materials as there are many other variables involved such as differences in equipment provision, student ability, changes in teaching provision and lack of networking in some parts of the laboratory.

Teaching staff were generally positive towards the use of online learning, and identified the following key benefits:

- Prepared lecture and practical notes online reduced the amount of pre-class preparation time required by established staff.

- New members of staff teaching on the modules had easy access to all the notes, this saved preparation time and gives a good indication of the range and standard of the material to be delivered.

- A common set of readily available notes enabled consistent delivery of material across the four modules in both teaching semesters. This was particularly true for staff teaching at the franchise college, enabling a comparable learning experience for students at both sites.

- The time needed for organizational tasks such as submitting notes for photocopying, filing and distributing handouts has been dramatically reduced. 
Staff identified some disadvantages: the preparation time for the development of standalone learning materials was high and a heavy burden. Preparation-time to study-time ratios for the lecture material was typically $10: 1$ while the practical tutorials the ratio was as high as 15:1. The dynamic nature of IT means that lecture and practical material needs to be updated on a regular basis and so the online learning resource will need to be edited frequently.

The WebCT (World Wide Web Course Tools) courseware-authoring tool developed at the University of British Columbia (Goldberg and Salari, 1997) has been adopted by the University's Electronic Campus initiative as its main design environment. This provides the courseware developer with communication, search and testing facilities. The existing content has imported into WebCT and is currently being piloted.

\section{Conclusions}

The study has some important implications from the perspective of the students. Design students view Web-based learning positively and do not need extrinsic motivation to utilize the technology. Student performance seems to be the same before and after the introduction of Web-based materials. The quality of the student learning experience is more consistent between sites and semesters, and material is more readily available to all students studying the modules, including franchise students, when it is on the Web. Students are more likely to access online resources within the university.

From a development perspective there are some lessons to be learnt. Online resources have high front-loaded development costs but, once generated, can result in a reduction of time needed to plan and organize course materials. However, releasing staff to work on development is not a simple matter of buying out time; there may be reasons why it is not possible to release key teaching staff. Large, multi-author projects introduce similar risks in meeting delivery and quality targets. These risks are exacerbated by the use of a low-cost external production company which introduces an element of risk in terms of the likelihood of meeting delivery and quality targets. The combination of a large multiauthor project with a low-cost production company is unlikely to result in course materials meeting cost, time and quality requirements.

\section{References}

Bacsich, P., Ash, C., Boniwell, K., Kaplan, L. (1999), The Costs of Networked Learning, Telematics in Education Research Group, Sheffield Hallam University.

Brown, S. (1997), Open and Distance Learning: Case Studies from Industry and Education, London: Kogan Page.

Brown, S. (1998), 'Reinventing the university', ALT-J, 6 (3), 30-7.

DfEE, (1998a), Towards a National Agenda: First Report of the National Skills Task Force, London: DfEE.

DfEE, (1998b), University for Industry, Pathfinder Prospectus, London: DfEE. 
HMSO, (1998), The Learning Age, UK Government Green Paper on Lifelong Learning, London: HMSO.

Georgeadou, E. and Higgett, N., (1997), 'Investigation into the design of WWW Based Educational Multimedia Modular Courseware', Proceedings of WebNet 97 Conference, Toronto, Canada.

Georgeadou, E. and Higgett, N., (1998), 'The design of Web-based hypermedia courseware in higher education', Proceedings of Graphicon 98 Conference, Moscow State University, Russia.

Goldberg, M. W. and Salari, S. (1997), 'An update on Web CT (World Wide Web Course Tools) - a tool for the creation of sophisticated Web-based learning environments', Proceedings of NAUWeb '97 - Current Practices in Web-based Course Development, Flagstaff, Arizona.

Laurillard, D. (1993), Rethinking University Teaching: A Framework for the Effective Use of Educational Technology, London: Routledge.

Littlejohn, A. H. and Stefani, A. J. (1999), 'Effective use of communication and information technology: bridging the skills gap', $A L T-J, 7$ (2), 66-76.

Zhao, Z., Higgett, N. and Cook, J. (1996), 'Online learning for design students', ALT-J, 4 (1), 69-76.

\section{Appendix I:The expectation questionnaire}

\section{Online teaching materials: What do you think?}

We are currently setting up a Web site to enable you to have access online to all the teaching materials that have been used in your Level I IT module.

To help us develop this site to meet the needs of next year's Level I students, we need your help. Please spend a few minutes filling in this questionnaire.

Name: (optional)

Degree programme:

1. Please rate how useful it would be to have access to the following materials on a mww site.

\begin{tabular}{lcccc} 
& Not useful & No opinion & Useful & Very useful \\
Lecture transcripts & - & - & - & - \\
Practical notes & - & - & - & - \\
Practical examples & - & - & - & - \\
Handbooks & - & - & - & - \\
Reading lists & - & - & - & - \\
Assignments & - & - & - & - \\
\hline
\end{tabular}


Sample test

Online discussion

Previous student work

$\begin{array}{ll}- & - \\ - & -\end{array}$

Is there anything eise that would be a valuable addition to the site?

2. If full transcripts of the lectures were held on line and you were not required to attend the weekly lecture, would you :

a. Still attend the weekly lecture ot the University?

Please tick one box

b. Still attend the weekly lecture and use the online resource as extra study material?

c. Use only the on line resource to study the lecture material?

I. Do you have Internet access at your term time address?

$$
\text { Yes _ No - }
$$

2. If you are taking CAD next year would you like to see the teaching materials for your Level 2 CAD module on line?

$$
\text { Yes - No - }
$$

Thank you for your help.

\section{Appendix 2:The feedback questionnaire}

\section{Online teaching materials, have you used them? What do you think?}

The teaching materials for your IT module have been available online in a developmental form this semester to provide an additional leaming resource. Please help us in our development of the resource by completing this questionnaire.

Name:

(optional)

Degree programme:

I. Have you used the online materials for the IT module this semester?

If no, please state the reason why

$$
\text { Yes - No - }
$$

If the answer above was yes go to the next question, if no go to question 5. 
2. Where have you accessed the online materials? Please tick as many options as necessary.

Fletcher CAD Lab, Floor 7

Kimberlin Library

Own computer

Friend's computer

Other

$$
\begin{aligned}
& - \\
& - \\
& - \\
& -
\end{aligned}
$$

3. Please rate how useful it has been to have access online to the following information.

$$
\text { Not useful No opinion Useful Very useful }
$$

Lecture tronscripts

Practical notes

Handbooks

Reading lists

$-$

$-$

$-$

$-$

4. As further additions to the site please rate how useful you think the following would be.

Not useful No opinion Useful Very useful

Practical examples

Assignments

Sample test

Online discussion

Previous student work

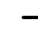

$-$

$-$

$-$

$-$
$-$

$-$

- $\quad-$

$-$

Other

5. What is the single greatest improvement that could be made to the resource?

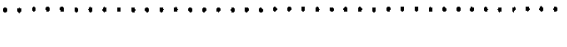

6. If you are taking CAD next year would you like to see the teaching materials for your Level 2 CAD module on line? Yes - No -

Thank you for your help. 